\title{
A study of the drugs used in chronic obstructive pulmonary disease and their impact on quality-of-life
}

\section{Vishal R. Mishra, Prakruti P. Patel ${ }^{1}$, Dikshit Ram Kumar', Chetna H. Patel ${ }^{3}$}

Department of Pharmacology, B.J. Medical college, Departments of ${ }^{1}$ Pharmacology and ${ }^{3}$ Physiology, B.J. Medical College, ${ }^{2}$ Department of Pharmacology, GCS Medical College, Ahmedabad, Gujarat, India

Address for the Correspondence:

Dr. Vishal R. Mishra, Department of Pharmacology, GMERS Medical College, Dharpur,

Patan, Gujarat, India E-mail: drvaz007@gmail.com

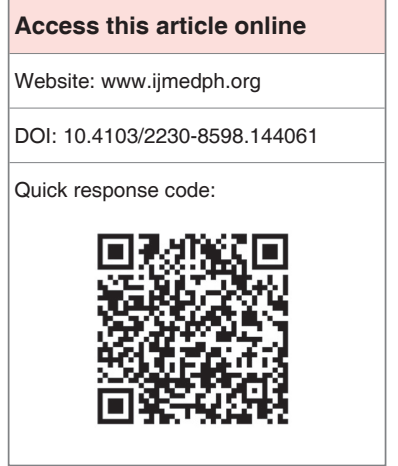

Objectives: The objective was to assess drugs used in treatment of chronic obstructive pulmonary disease (COPD) and their impact on quality-of-life. Materials and Methods: All newly diagnosed patients visiting the pulmonary medicine OPD were enrolled for the study based on inclusion and exclusion criteria. All patients were followed up for 6 months. Symptom and drug therapy assessment was done every month, while spirometry and quality-of-life assessment was done every 2 months. St. George Respiratory questionnaire was used for quality-of-life assessment. Results: A total of 100 patients was enrolled in the study, 78 were males and 22 females with mean age being $58.91 \pm 6.58$ years. All 84 patients, who were smokers, smoked bidis. Statistically significant improvement was seen in dyspnea, while all other symptoms did not show such improvement. 26 patients suffered from mild COPD, 48 had a moderate severity while remaining 26 belonged to the severe form of the disease. Improvement was seen in all parameters of spirometry. Statistically significant improvement was seen in forced expiratory volume at $1 \mathrm{~s}\left(\mathrm{FEV}_{1}\right)$ at 4 and 6 months, in forced vital capacity at 6 months, in FEV $_{1} \%$ at 4 and 6 months as compared to baseline. Peak expiratory flow and forced expiratory flow 25-75 also showed statistically significant improvement at every follow-up as compared to baseline. Methylxanthines, anticholinergics, $\beta_{2}$ agonists, and corticosteroids were the commonly prescribed drugs. Improvement was seen in quality-of-life but overall improvement was not clinically significant. A decrease in total score in quality-of-life was seen from 44.63 at baseline to 41.76 at the end of

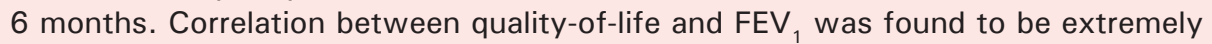
significant. Conclusion: Improvement in quality-of-life was not clinically significant. However, correlation between $\mathrm{FEV}_{1}$ and quality-of-life was extremely significant.

Key words: Chronic obstructive pulmonary disease, quality-of-life, spirometry

\section{INTRODUCTION}

Chronic obstructive pulmonary disease (COPD) is the fourth most common cause of death in the world. ${ }^{[1]}$ An estimated 64 million people had COPD worldwide in 2004. More than 3 million people died of COPD in 2005, which is equal to $5 \%$ of all deaths globally that year. Almost $90 \%$ of COPD deaths occur in low- and middle-income countries. ${ }^{[1]}$ COPD is the second most common cause of death among noncommunicable diseases in India. In 2010, almost 24 million adults over the age of 40 in India had COPD. This is expected to increase to 34\% or approximately 32 million by 2020 . Prevalence rates varying from about $2 \%$ to $22 \%$ in men and from $1.2 \%$ to $19 \%$ in women have been shown in different reports. ${ }^{[2]}$ Drugs used in management of COPD do not cure the disease but only control the symptoms and slow the disease progression..$^{[3]}$ They include bronchodilators such as $\beta$ agonists, anticholinergics, methylxathines, and glucocorticoids. Recently, phosphodiesterase-4 inhibitors have also been used in treatment of COPD. Bronchodilators play a key role in symptomatic management of COPD. ${ }^{[3]}$

The traditional approach of caring for patients with chronic respiratory disease has been to rely on pulmonary function tests to quantify the severity and to assess the response to therapy. However, patients with respiratory conditions seek medical attention due to symptoms, particularly dyspnea and 
impaired ability to function, which clearly impact on an individual's health-related quality-of-life (HRQOL). Selected studies using disease-specific instruments have demonstrated that $\beta 2$-agonist, anticholinergics, and theophylline medication can improve HRQOL, as compared to the placebo therapy. ${ }^{[4]}$ One such instrument for measuring HRQOL is St. George Respiratory Questionnaire (SGRQ). SGRQ has been developed for measuring HRQOL in respiratory diseases like asthma and COPD. ${ }^{[5]}$ There have been no studies so far in our institute to measure quality-of-life of patients. Therefore, the present study was undertaken to study the drugs prescribed in patients of COPD, to study the impact of these drugs on quality-of-life, to compare the change in quality-of-life with change in pulmonary function tests, and to monitor any adverse drug reactions (ADRs) occurring during the course of the given treatment.

\section{MATERIALS AND METHODS}

This was a continuous, longitudinal, prospective, observational, single centre study, conducted between September 2010 and June 2012, carried out at the COPD clinic of the Department of Pulmonary Medicine at a tertiary care teaching hospital in Western India. Prior permission to conduct the study was obtained from Institutional Ethics Committee and Head of Unit, Department of Pulmonary Medicine. All newly diagnosed patients of COPD (as per GOLD guidelines) attending pulmonary medicine OPD of either gender who are willing to participate and giving informed consent were included in the study. Patients having very severe $\mathrm{COPD},{ }^{[3]}$ cor pulmonale or having concomitant medical disorders like cardiac disease, hypertension, tuberculosis, etc., that could affect the quality-of-life outcome were excluded.

After a provisional diagnosis, patients were asked to undergo spirometric examination using spirometer (MIR spirolab Italy) which helped in confirming the diagnosis of COPD and classifying the disease severity. Quality-of-life was measured using SGRQ administered in vernacular language. Each patient was followed monthly for next 6 months. Quality-of-life assessment and spirometry were performed every 2 months (i.e., at the end of 2 months, 4 months, and 6 months). The data were recorded in Microsoft Excel Worksheet version 2007 (Microsoft corporation U.S.). Quality-oflife scores were calculated using a score calculator, (provided by the original source) and statistical evaluation was done using the Chisquare test and paired and unpaired Student's $t$-test with the help of GraphPad Demo version software (Graphpad software Inc. U.S.). $P<0.05$ was considered to be statistically significant. Minimal clinical important difference (MCID) of 4 units in SGRQ was considered as clinically significant. ${ }^{[6]}$ Analysis of the suspected ADRs and their causality assessment were done by WHO-UMC and Naranjo et al. probability score. ${ }^{[7]}$ The severity and preventability were assessed by scales described by Hartwig et al. modified by Lau et al. respectively. ${ }^{[8,9]}$

\section{RESULTS}

A total of 108 patients was enrolled during the study period and was followed up monthly for a period of 6 months. Of 108 patients, 100 patients completed the study and 8 were lost to follow-up. Mean age of the enrolled patients was $58.91 \pm 6.58$ years and mean weight of the patients was $53.59 \pm 5.48 \mathrm{~kg}$. There were 48 illiterate patients, 28 had primary education, 22 patients were matriculate, and the remaining 12 were graduates. Of 78 male patients, 48 (48\%) were laborers, $10(10 \%)$ were vegetable and fruit vendors, 8 (8\%) were shop keepers while $6(6 \%)$ patients worked as mill workers. Six patients were not employed due to illness. All female patients (22) were housewives. However, 5 of them were not able to work properly even at home due to illness. Eighty-three patients belonged to the low income group with yearly income $<40,000$ rupees.

Of 100 patients, 61 patients reported irregular attendance at work due to the disease. Sixty-three patients reported seasonal change in disease severity, that is, it was more severe in winter. Alcohol was consumed by 12 patients, while tobacco chewing was reported by 8 . Smoking history was positive in 84 patients, 68 were active smokers while 16 were passive. All the smokers used bidis. An average of one and half pack of bidis was smoked per day (range 0.5-4 packs/day). Average duration of smoking was 20 years (range 8-30 years). Average pack-years of smoking were found to be 30 . Mean number of episodes of respiratory tract infection during last 1 year was 2 (range: $1-4)$.

The most common presenting complaint was breathlessness (dyspnea) (96), followed by cough (80). Other symptoms included excessive sputum (29), nocturnal cough (28), wheezing (19), fever and body ache. All symptoms were assessed every month for 6 months. Statistically significant $(P<0.05)$ reduction in dyspnea was observed at the end of 3 months as compared to baseline. This continued for the entire duration of the study. Similarly, statistically significant reduction was also observed in cough by the end of 2 months and the reduction continued until the end of study period. All other symptoms decreased over the period of 6 months but the difference was statistically insignificant.

Mean respiratory rate was found to be $26.3 \pm 6.2 /$ min (range 19-32) at baseline. Rhonchi was heard on auscultation in nearly all the patients (99), wheezing was present in 24 while accessory muscle use was seen in 6 patients. A reduction in mean respiratory rate was noted at each follow-up, reduction being statistically significant at $4^{\text {th }}$, $5^{\text {th }}$, and $6^{\text {th }}$ follow-up as compared to baseline. On the other hand, decrease in rhonchi was statistically significant at every visit starting from $1^{\text {st }}$ follow up. However, decrease in wheezing and accessory muscle use was statistically insignificant at all follow-up examinations.

\section{Spirometry}

Pulmonary function tests were performed at baseline, $2^{\text {nd }}, 4^{\text {th }}$, and $6^{\text {th }}$ follow-up. Parameters recorded were forced expiratory volume at $1 \mathrm{~s}\left(\mathrm{FEV}_{1}\right)$, forced vital capacity (FVC), percentage of $\mathrm{FEV}_{1} \%$, peak expiratory flow rate (PEFR), and forced expiratory flow (FEF). It was observed that on basis of $\mathrm{FEV}_{1} \%, 26$ patients suffered from mild COPD, 48 had a moderate severity while remaining 26 belonged to the severe form of the disease. Improvement was seen 
in all parameters of spirometry. There was statistically significant improvement in $\mathrm{FEV}_{1}$ at 4 and 6 months, in FVC at 6 months, in $\mathrm{FEV}_{1} \%$ at 4 and 6 months as compared to baseline [Table 1]. PEF and FEF 25-75 also showed statistically significant improvement at every follow-up as compared to baseline.

\section{Drug therapy}

Methylxanthines, anticholinergics, $\beta_{2}$ agonists, and corticosteroids were commonly prescribed drugs [Table 2]. A fixed dose combination of etophylline + theophylline was prescribed in all patients (100). Other commonly prescribed combinations were tiotropium + formoterol, salmeterol + fluticasone, ipratropium + salbutamol and formoterol + budesonide. Triple drug combinations were also prescribed in 17 patients as seen in the table. Etophylline + theophylline combination was prescribed by oral route (three times a day) while all other drugs were given by inhalation using dry powder rotahalers (usually 2-3 times a day).

Several other drugs were also prescribed in addition to the abovementioned treatment as and when required, which included $\mathrm{H}_{2}$ blockers and proton pump inhibitors (64), multivitamins (58), cough and cold mixtures (14), antimicrobials (13), mucolytics (12), and antipyretic agents (8).

\section{Quality-of-life}

Quality-of-life was assessed at baseline and at the end of $2^{\text {nd }}, 4^{\text {th }}$, and $6^{\text {th }}$ month using SGRQ. ${ }^{[5]}$ A total of 16 items which included questions regarding patients' recollection of their symptoms and their perception about their current health status. Three different scores quality-of-life of COPD patients were:
a. Mean symptoms score,
b. Mean activity score, and
c. Mean impact score [Table 3].

The baseline mean symptoms score was 54.8 , mean activity score was 44.8 , and mean impact score was 40.83. A mean total score of these three was 44.63. All these scores were calculated at each assessment and the comparison was made. A decrease in total score was seen from 44.63 at baseline to 41.76 at the end of 6 months. Improvement was seen in all the three scores at each follow-up as seen in Table 3, but overall improvement was not clinically significant.

It has been postulated that a difference of at least 4 units must exist for the results to be considered as clinically significant. This difference is also labeled as "MCID" or "clinical threshold."[6] Since decrease in mean total score (MCID) in our study was observed to be $<4$, the improvement in quality-of-life cannot be considered as clinically significant. However, a closer scrutiny of the results indicated that this difference was $>4$ units in case of mean symptoms score ( 54.8 vs. 50.1 ). The improvement, however, is not observed in routine physical activity and psychosocial functioning. A comparison of the mean scores was also made according to the severity of the disease [Figure 1]. No appreciable change was observed in any of the scores in case of patients suffering from moderate to severe form of disease. However, clinically significant difference was seen in mean symptoms score (5.3 units), mean activity score (4.5 units), and mean total score (4 units) at the end of 6 months in patients suffering from mild form of the disease. Twenty-five patients (25\%) showed MCID

\begin{tabular}{|c|c|c|c|c|}
\hline Parameter & $\begin{array}{l}\text { Baseline } \\
\text { value }\end{array}$ & 2 months & 4 months & 6 months \\
\hline $\mathrm{FEV}_{1}(\mathrm{~L})$ & $2.60 \pm 0.48$ & $2.72 \pm 0.52$ & $2.79 \pm 0.39^{*}$ & $2.81 \pm 0.51^{*}$ \\
\hline FVC (L) & $3.86 \pm 0.55$ & $3.94 \pm 0.61$ & $4.03 \pm 0.63$ & $4.14 \pm 0.54^{*}$ \\
\hline $\mathrm{FEV}_{1}(\%)$ & $66.49 \pm 17.10$ & $69.94 \pm 19.31$ & $74.41 \pm 17.34^{*}$ & $75.44 \pm 19.30$ * \\
\hline PEF (L/s) & $7.78 \pm 0.53$ & $8.06 \pm 0.71^{*}$ & $8.19 \pm 0.83^{*}$ & $8.33 \pm 0.89^{*}$ \\
\hline $\mathrm{FEF}_{25-75}(\mathrm{~L} / \mathrm{s})$ & $3.72 \pm 0.2$ & $4.04 \pm 0.41^{*}$ & $4.09 \pm 0.44^{*}$ & $4.11 \pm 0.50^{*}$ \\
\hline
\end{tabular}

Values shown are mean \pm SD. $* P<0.05$, as compared to baseline (Student's $t$-test). $\mathrm{FEV}_{1}=$ Forced expiratory volume at $1 \mathrm{~s}, \mathrm{FVC}=$ Forced vital capacity, $\mathrm{FEV}_{1}(\%)=$ Percentage of forced expiratory volume at $1 \mathrm{~S}, \mathrm{PEF}=$ Peak expiratory flow, $\mathrm{FEF}_{25-75}=$ Forced expiratory flow (25-75), SD = Standard deviation, $\mathrm{COPD}=$ Chronic obstructive pulmonary disease

\begin{tabular}{|c|c|c|}
\hline Drugs prescribed & Dose & $\begin{array}{l}\text { Number of } \\
\text { patients }\end{array}$ \\
\hline \multicolumn{3}{|l|}{ Methylxanthines } \\
\hline $\begin{array}{l}\text { Etophylline+theophylline } \\
\text { (deriphylline) }\end{array}$ & 77 mg+23 mg (100 mg) & 100 \\
\hline \multicolumn{3}{|l|}{$\begin{array}{l}\text { Anticholinergic }+\beta_{2} \\
\text { agonist }\end{array}$} \\
\hline Tiotropium+formoterol & $18 \mu \mathrm{g}+12 \mu \mathrm{g}$ & 26 \\
\hline \multirow[t]{2}{*}{ Ipratropium+salbutamol } & $40 \mu \mathrm{g}+200 \mu \mathrm{g}$ & 15 \\
\hline & & $\begin{array}{l}\text { Total: } 41 \\
\text { patients }\end{array}$ \\
\hline \multicolumn{3}{|l|}{$\beta_{2}$ agonist + corticosteroids } \\
\hline Salmeterol+fluticasone & $50 \mu \mathrm{g}+100 \mu \mathrm{g}$ & 17 \\
\hline \multirow[t]{2}{*}{ Formoterol+budesonide } & $6 \mu \mathrm{g}+100 \mu \mathrm{g}$ & 12 \\
\hline & & $\begin{array}{l}\text { Total: } 29 \\
\text { patients }\end{array}$ \\
\hline \multicolumn{3}{|l|}{ Anticholinergic } \\
\hline Tiotropium & $18 \mu \mathrm{g}$ & 13 \\
\hline \multicolumn{3}{|l|}{$\begin{array}{l}\beta_{2} \text { agonist+anticholinergi } \\
\text { c+corticosteroids }\end{array}$} \\
\hline $\begin{array}{l}\text { (Tiotropium+formoterol) } \\
\text { +budesonide }\end{array}$ & $(18 \mu \mathrm{g}+12 \mu \mathrm{g})+100 \mu \mathrm{g}$ & 8 \\
\hline \multirow{2}{*}{$\begin{array}{l}\text { (Salmeterol+fluticasone) } \\
\text { +tiotropium }\end{array}$} & $(50 \mu \mathrm{g}+100 \mu \mathrm{g})+18 \mu \mathrm{g}$ & 9 \\
\hline & & $\begin{array}{l}\text { Total: } 17 \\
\text { patients }\end{array}$ \\
\hline
\end{tabular}

COPD $=$ Chronic obstructive pulmonary disease

\begin{tabular}{|c|c|c|c|c|}
\hline $\begin{array}{l}\text { Quality-of-life } \\
\text { parameter }\end{array}$ & $\begin{array}{c}\text { Baseline } \\
\text { score }\end{array}$ & 2 months & 4 months & 6 months \\
\hline $\begin{array}{l}\text { Mean symptom } \\
\text { score }\end{array}$ & 54.8 & 51.6 & 50.8 & 50.1 \\
\hline Mean activity score & 44.8 & 43.1 & 42.7 & 42.2 \\
\hline Mean impact score & 40.83 & 38.61 & 38.43 & 37.98 \\
\hline Mean total score & 44.63 & 42.91 & 42.09 & 41.76 \\
\hline
\end{tabular}




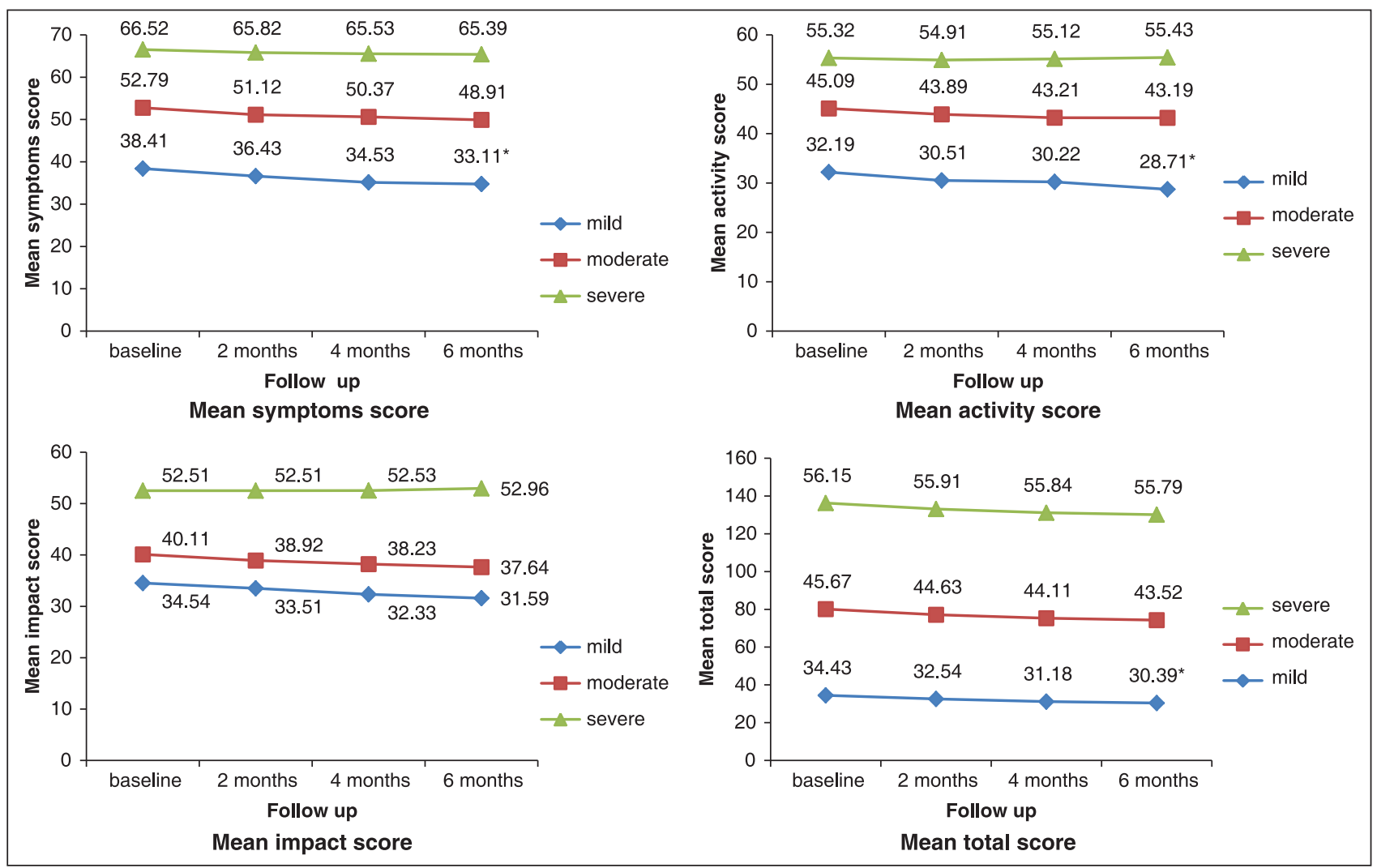

Figure 1: Changes in quality-of-life scores based on disease severity of patients suffering from chronic obstructive pulmonary disease. A decrease in score indicates an improvement in quality-of-life. ${ }^{*}$ Minimal clinically significant difference of $>4$ units

of $>4$ units at the end of the study period. Of these, 14 patients belonged to mild category; eight patients had moderate disease, while three patients were from the severe category. It was observed that maximum benefit in quality-of-life is seen in patients suffering from mild form of the disease as stated above. It is much lesser in those suffering from moderate form of the disease and least in the patients of severe form of COPD.

Correlation between quality-of-life and $\mathrm{FEV}_{1}$ was estimated using Pearson Parametric Correlation Test [Figure 2]. Difference of mean $\mathrm{FEV}_{1}$ was calculated using baseline and the final (6 months) values. Similar difference of mean was also calculated for quality-of-life score. Since quality-of-life score decreased over the period of 6 months, the mean difference was negative. Correlation coefficient (r) calculated was -0.59 , confidence interval (95\%) being -0.71 to -0.45 and coefficient of determination $\left(r^{2}\right)$ was 0.35 . Thus, this correlation was extremely significant $(P<0.0001)$, which means that improvement in $\mathrm{FEV}_{1}$ strongly correlates with improvement in quality-of-life. About $8 \%$ (6) of total patients belonging to moderate and severe category of disease reported that quality-of-life had worsened at 6 months as compared to baseline.

The drug therapy was well-tolerated. Totally, six ADRs were reported during the study period which included dryness of mouth (3), oral candidiasis (2), and tremor (1). Suspected medications were tiotropium, budesonide, and salmeterol, respectively. All the reactions were nonserious and mild in nature, and all patients

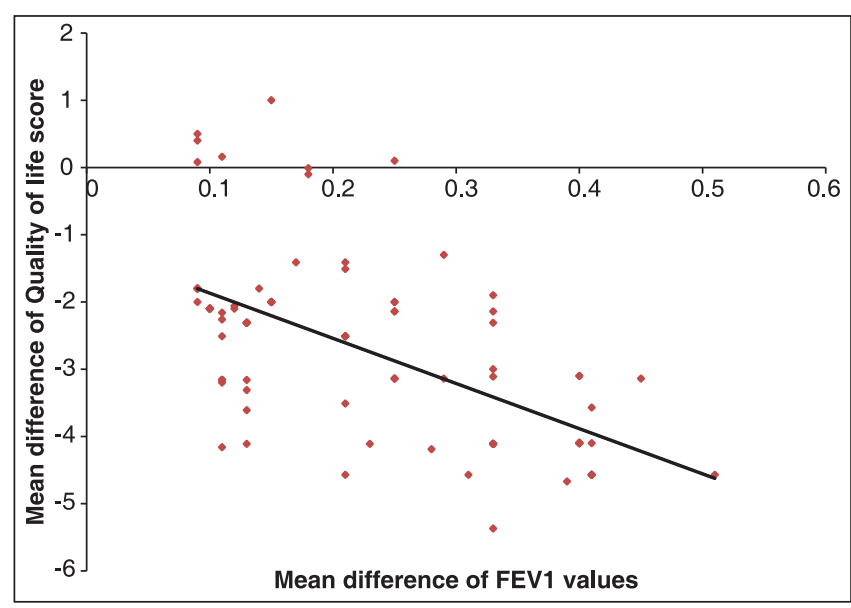

Figure 2: Correlation between forced expiratory volume at $1 \mathrm{~s}$ and total quality-of-life score values are difference of means of individual patients at baseline and at 6 months

recovered from them. Causal relationship between ADRs and drugs was probable in nature and probably preventable.

\section{DISCUSSION}

Mean age of the patients in our study was $58.91 \pm 6.58$ years. This is similar to the observations made in United States ${ }^{[10]}$ and Denmark, ${ }^{[1]}$ where mean age was of the patients of COPD was reported to be 
56 and 59 years, respectively. Majority of the patients in our study were $>60$ years of age ( $44 \%$ ), which supports the view that COPD prevalence increases with age. ${ }^{[12]}$ About half of the patients in our study were illiterate $(48 \%)$, which may result into a poor level of health awareness. A study in United States has shown that literacy in COPD is linked to the severe form of the disease and poor qualityof-life. ${ }^{[13]}$ Nearly half of the patients in our study were laborers and they are quite likely to use tobacco in any form and hence, likely to suffer from COPD. ${ }^{[14]}$ In addition, they also get an increased exposure to environmental smoke and pollution which promote the development of COPD.$^{[3]}$ Eighty-seven patients in our study belonged to the poor socioeconomic status. This is expected at a Government Hospital, where bulks of the services provided are free of cost and which caters mainly to the lower socioeconomic groups. Furthermore, poverty is a clear risk factor for COPD, as studies have shown that risk of developing COPD is inversely proportional to socioeconomic status. ${ }^{[15]}$

Sixty-three patients in our study reported that disease was more severe in winter. A higher severity of disease in winter has also been reported by studies conducted in United Kingdom. ${ }^{[16]}$ Possible explanations include increased disease exacerbations and increased influenza infection in winter. ${ }^{[16]}$ Smoking has been mentioned as a clear risk factor for development of COPD. ${ }^{[3]}$ In our study, 84 patients were smokers, 68 active, and 16 passive. Similar prevalence of smoking among COPD patients has been reported by studies conducted in Denmark ${ }^{[11]}$ and Poland. ${ }^{[17]}$ Studies have shown a negative correlation with smoking, number of pack years, and quality-of-life. ${ }^{[18,19]}$

Drug therapy has proven to be effective in providing effective symptomatic relief in patients of COPD. ${ }^{[20]}$ Statistically significant reductions were seen in dyspnea and cough during follow-up. A significant decrease in rhonchi was also noted at every visit starting from $1^{\text {st }}$ follow-up. Decrease in inflammation of the airways causes a reduction in secretions and rhonchi. ${ }^{[21]}$ According to classification of disease severity, based upon the percent value of $\mathrm{FEV}_{1}$ as per spirometric investigation, ${ }^{[3]} 26$ patients in our study suffered from mild COPD, 48 had a moderate severity while remaining 26 belonged to the severe form of the disease. Improvement was seen in all parameters of spirometry in the present study. Statistically significant improvement was seen in $\mathrm{FEV}_{1}$ at 4 and 6 months as compared to baseline. Similar improvement has also been reported by others. ${ }^{[22,23]}$ A significant improvement was also seen in the present study in FVC and PEFR as has also been reported by Casaburi et al. and Vincken et al. ${ }^{[22,23]}$ However, a multicenter trial of tiotropium (UPLIFT) has revealed a decline in all spirometric values as compared to baseline. ${ }^{[24]}$ Closer analysis of the UPLIFT study reveals that there was an improvement in all spirometric values until 6-12 months of the study and this was followed by a decline. ${ }^{[24]}$ This is difficult to explain but may either be due to the natural course of the disease, poor compliance to the treatment or a resistance to it.

We noted that a fixed dose combination of theophylline + etophylline (deriphylline) was prescribed in all the patients which was available free of cost in government supply. This is much more than what has been reported by others elsewhere particularly in developed countries. ${ }^{[22,23]}$ Global initiative for obstructive lung disease ${ }^{[3]}$ has recommended that methylxanthines should not be prescribed to patients of COPD if inhaled long acting bronchodilators are available. However, they are still commonly employed in India due to low cost. ${ }^{[27]}$ Anticholinergics, alone or in fixed dose combinations were prescribed in 71 patients. This is similar to what has been reported by others. ${ }^{[22,23]}$ GOLD has recommended routine use of $\beta_{2}$ agonists in management of COPD patients. $\beta_{2}$ agonists, short acting alone or in combination and long acting in combination with anticholinergics, were prescribed in our study in $87 \%$ patients which included salbutamol, salmeterol, and formoterol which is more or less same as observed by others. ${ }^{[2,23]}$ GOLD recommends that longterm treatment with inhaled corticosteroids be given to patients with severe and very severe disease and for frequent exacerbations that are not adequately controlled by bronchodilators. We observed that inhaled corticosteroids, alone or in combination, were prescribed commonly and this included budesonide and fluticasone. Similar rate of prescription of inhaled corticosteroids was noted in an American study. ${ }^{[22]}$ However, prescription rates were significantly higher $(80-86 \%)$ in Belgium ${ }^{[23]}$ and Netherlands. ${ }^{[26]}$ The difference may be due to the fact that 26 patients in our study had mild COPD and they did not require inhaled corticosteroids for disease management, while Belgian ${ }^{[23]}$ and Dutch ${ }^{[26]}$ studies may have contained a higher number of patients with severe and very severe COPD as baseline mean $\mathrm{FEV}_{1}$ values were also significantly lower in these studies as compared to ours (1.10 vs. $2.60 \mathrm{~L} / \mathrm{s})$. Concomitant drugs were prescribed in the present study as and when needed. Cough and cold mixtures, mucolytics, and antibiotics were prescribed usually as per GOLD guidelines as prescription was not routine. However, prescription of $\mathrm{H}_{2}$ blockers, omeprazole, and multivitamins was irrational and should be avoided. Six ADRs were reported during this study. The incidence of ADRs as observed by us was significantly less than a study conducted in New Delhi where it was about 31\%. ${ }^{[27]}$ Under-reporting due to lack of awareness cannot be ruled out in the present study.

Quality-of-life was assessed using SGRQ. Quality-of-life depends nearly equally on all aspects of assessment viz., symptom control, ability to carry out routine physical activity, and the psycho-social adequacy of the patient. Improvement was seen in all the three scores in our study at all follow-ups. Furthermore, mean total score decreased from 44.63 to 41.76 (mean difference 2.87 units). Since decrease in mean total score in our study was <4 (MCID), the improvement in quality-of-life cannot be considered as clinically significant. Similarly, a meta-analysis of 22 studies with a total data of about 22,000 patients has also reported the mean reduction in total score to be 3.19 units. ${ }^{[28]}$ However, we also observed that this difference was $>4$ units in case of mean symptoms score (54.8 vs. 50.1). This was expected as an improvement was seen in all the symptoms of COPD, and statistically significant reduction was noted in dyspnea and cough. It is possible that there was a clinically important difference as far as the symptomatic relief is concerned 
and this did offer some improvement in quality-of-life that was not enough to result into a clinically significant total quality-of-life. It is also evident that a matching improvement could not take place in routine physical activity and psychosocial functioning. Our findings are in agreement with Casaburi et al., and Tonnel et al. ${ }^{[22,29]}$ It has been reported that reduction in the frequency of dyspnea and exacerbations of the disease may account for the feeling of improvement ${ }^{[22]}$ as was also observed in our study. Maximum reduction was seen in symptoms score in the present study. This gives rise to an impression that clinically, a great deal of importance is attached to alleviation of the symptoms and the currently available drug therapy is competent enough to elicit the desired therapeutic benefit. It further goes on to show that an overall improvement in quality-of-life requires an equal and adequate attention to be paid to the physical ability of the patient as well as his/her mental status in addition to the relief of the symptoms. Clearly, one needs to do more besides providing an effective drug therapy.

In our study, mean difference in total score of quality-of-life between baseline (44.63) and at 6 months (41.76) was $-2.87 \pm 1.28$ units. Confidence interval (95\%) of this observation was calculated using 2 SDs. Lower value of confidence interval was below -4 units and upper limit was below zero. Hence, here the treatment effect can be considered as clinically significant, that is, the benefit is small but clinically significant. Similar outcomes have been reported by various studies conducted in France ${ }^{[29]}$ and America. ${ }^{[30]}$ In the present study, analysis of subgroups of patients based on disease severity indicated that maximum benefit is shown in patients suffering from mild COPD, where a clinically significant improvement was seen in mean total score (4 units), mean symptoms score (5.3 units), and mean activity score ( 4.5 units). No appreciable change was observed in any of the scores in case of patients suffering from moderate to severe forms of disease. GOLD has stated that there is an increased risk of exacerbation, hospitalization, and death with worsening of airflow limitation (in moderate and severe forms of the disease). ${ }^{[3]}$ This implies that more severe the disease, more are the number of exacerbations (and other complications) which will have a negative impact on quality-of-life. ${ }^{[31]}$ Thus, it seems that there are less chances of improvement in quality-of-life in patients suffering from a severe form of the disease. Twenty-five patients (25\%) improved by 4 units or more (MCID) at the end of the study period. This was significantly lower as compared to the American study ${ }^{[22]}$ where it was observed in nearly double the number of patients and a similar improvement (48.1\%) was reported by a recent multicentric trial of aclidinium. ${ }^{\text {[25] }}$ It is difficult to explain a greater amount of improvement in other studies as compared to the present work. It is speculated that the difference in patient or disease characteristics may be the cause.

A correlation between quality-of-life score and $\mathrm{FEV}_{1}$ was also made to determine the relationship between these two parameters. Correlation coefficient $(r)$ calculated was -0.59 . This correlation was extremely significant $(P<0.0001)$. This implies that there is a strong inverse relationship between quality-of-life score and $\mathrm{FEV}_{1}$. Similar relationship has been demonstrated in Swedish ${ }^{[32]}$ and American studies. ${ }^{[33]}$ An Indian study also reported statistically significant correlation between SGRQ total score and $\mathrm{FEV}_{1}(r=-0.39$, $P<0.001)$. However, GOLD describes a poor correlation between quality-of-life score and $\mathrm{FEV}_{1}$ values $(r=-0.23) .{ }^{[3]}$ Correlation between mean difference of quality-of-life score and $\mathrm{FEV}_{1}$ has been stronger in our study. Studies mentioned above have used absolute values of total scores and $\mathrm{FEV}_{1}$ for comparison, while we have employed mean difference between baseline and final values of the mean total score and $\mathrm{FEV}_{1}$ to assess the relationship. This may be the reason for higher correlation observed in the present study. Thus, it can be proposed that the quality-of-life assessment may serve as a useful alternative to spirometry for disease assessment at follow-ups.

\section{CONCLUSION}

To conclude, we may say that the overall improvement in total quality-of-life score in patients of COPD was small but may be clinically significant. An advanced age (>60 years), poor socioeconomic status, smoking, and moderate to severe forms of the disease may be responsible for this. It is recommended that besides providing an optimum drug treatment that relieves the current symptoms of the disease, attempts should also be made to enable the patient to remain physically self-dependent. In addition, a psycho-social support will also be required to obtain a significant improvement in quality-of-life.

Our study had some limitations. The number of patients enrolled in our study were relatively small (one hundred only). A larger cohort would have given us a better idea of epidemiology of the disease and impact of the drug therapy on quality-of-life. Drug therapy prescribed was usually empirical. Hence, intergroup comparison based on different drug treatments cannot be made either due to smaller sample size or due to similar drugs having been prescribed to the patients of varying disease severity. However, importance of the present study cannot be undermined. It is one of the few studies to be conducted in India on quality-of-life in patients of COPD. It may be the first Indian study which has attempted to study the impact of drug therapy on quality-of-life in these patients. Our study has reported a significant improvement in quality-of-life seen in mild category of patients and very significant correlation between qualityof-life and $\mathrm{FEV}_{1}$. This work may prove to be a foundation for future research on quality-of-life in COPD and may also help physicians in deciding treatment options based upon it rather than spirometry.

\section{REFERENCES}

1. World Health Organization. Global Status Report on Non-Communicable Diseases 2010. Geneva: WHO; 2010. Available from: http://www.who.int/ nmh/publications/ncd_report_full_en.pdf. [Last accessed on 2013 Jul 14].

2. Report of the Working Group on Disease Burden for $12^{\text {th }}$ Five Year Plan. WG3 (2): Non Communicable Diseases. Available from: http:// www.planningcommission.nic.in//WG_3_2non_communicable.pdf/. [Last accessed on 2013 Jul 08].

3. Global Strategy for the Diagnosis, Management, and Prevention of Chronic Obstructive Pulmonary Disease. Global Initiative for Chronic Obstructive Lung Disease (GOLD) 2011. Available from: http://www. goldcopd.org. [Last accessed on 2012 Sep 06]. 
4. Gupta B, Kant S. Health related quality of life (HRQOL) in COPD. Internet J Pulmonary Med 2009;11:1.

5. Jones PW, Quirk FH, Baveystock CM, Littlejohns P. A self-complete measure of health status for chronic airflow limitation. The St. George's Respiratory Questionnaire. Am Rev Respir Dis 1992;145:1321-7.

6. Jones PW. Interpreting thresholds for a clinically significant change in health status in asthma and COPD. Eur Respir J 2002;19:398-404.

7. Naranjo CA, Busto U, Sellers EM, Sandor P, Ruiz I, Roberts EA, et al. A method for estimating the probability of adverse drug reactions. Clin Pharmacol Ther 1981;30:239-45.

8. Hartwig SC, Siegel J, Schneider PJ. Preventability and severity assessment in reporting adverse drug reactions. Am J Hosp Pharm 1992:49:2229-32.

9. Lau PM, Stewart K, Dooley MJ. Comment: Hospital admissions resulting from preventable adverse drug reactions. Ann Pharmacother 2003:37:303-4.

10. Mapel DW, Dutro MP, Marton JP, Woodruff K, Make B. Identifying and characterizing COPD patients in US managed care. A retrospective, cross-sectional analysis of administrative claims data. BMC Health Serv Res 2011;11:43.

11. Vestbo J, Sørensen T, Lange P, Brix A, Torre P, Viskum K. Long-term effect of inhaled budesonide in mild and moderate chronic obstructive pulmonary disease: A randomised controlled trial. Lancet 1999;353: 1819-23.

12. Mannino DM. Chronic obstructive pulmonary disease: Epidemiology and evaluation. Hosp Physician 2001;22:22-31.

13. Baernholdt M, Hinton I, Yan G, Rose K, Mattos M. Factors associated with quality of life in older adults in the United States. Qual Life Res 2012;21:527-34.

14. Subramanyam VB, Pratap M, Indira P. A comparative study on the prevalence of occupational respiratory symptoms age wise in male and female labourers of cement industries in Tadipatri Mandal of Anantapur District, Andhra Pradesh. Asian J Environ Sci 2009;4:43-7.

15. Prescott E, Bjerg AM, Andersen PK, Lange P, Vestbo J. Gender difference in smoking effects on lung function and risk of hospitalization for COPD: Results from a Danish longitudinal population study. Eur Respir J 1997;10:822-7.

16. Burge S, Wedzicha JA. COPD exacerbations: Definitions and classifications. Eur Respir J Suppl 2003;41:46s-53.

17. Szafranski W, Cukier A, Ramirez A, Menga G, Sansores R, Nahabedian S, et al. Efficacy and safety of budesonide/formoterol in the management of chronic obstructive pulmonary disease. Eur Respir J 2003;21:74-81.

18. Nunes DM, Mota RM, de Pontes Neto OL, Pereira ED, de Bruin VM, de Bruin PF. Impaired sleep reduces quality of life in chronic obstructive pulmonary disease. Lung 2009;187:159-63.

19. Spencer S, Calverley PM, Sherwood Burge P, Jones PW, ISOLDE Study Group. Inhaled Steroids in Obstructive Lung Disease. Health status deterioration in patients with chronic obstructive pulmonary disease. Am J Respir Crit Care Med 2001;163:122-8.

20. William DM, Bourdet SV. Chronic obstructive pulmonary disease. In: Dipiro JT, Talbert RL, Yee GC, Matzke GR, Wells BG, Posey LM, editors.
Pharmacotherapy: A Pathophysiologic Approach. New York: Mc-Graw Hill; 2008. p. 495-517.

21. Wright JL, Senior RM, Wise RA, Rennard SI, Ries AL, Atkinson JL, et al. Chronic obstructive pulmonary disease. In: Fishman AP, Elias JA, Fiashman JA, Grippi MA, Senior RM, Pack Al, editors. Fishman's Pulmonary Diseases and Disorders. New York: Mc-Graw Hill; 2008. p. 693-773.

22. Casaburi R, Mahler DA, Jones PW, Wanner A, San PG, ZuWallack RL, et al. A long-term evaluation of once-daily inhaled tiotropium in chronic obstructive pulmonary disease. Eur Respir J 2002;19:217-24.

23. Vincken W, van Noord JA, Greefhorst AP, Bantje TA, Kesten S, Korducki L, et al. Improved health outcomes in patients with COPD during 1 yr's treatment with tiotropium. Eur Respir J 2002;19:209-16.

24. Morice AH, Celli B, Kesten S, Lystig T, Tashkin D, Decramer M. COPD in young patients: A pre-specified analysis of the four-year trial of tiotropium (UPLIFT). Respir Med 2010;104:1659-67.

25. Jones PW, Rennard SI, Agusti A, Chanez P, Magnussen H, Fabbri L, et al. Efficacy and safety of once-daily aclidinium in chronic obstructive pulmonary disease. Respir Res 2011;12:55.

26. Franssen FM, Spruit MA, Wouters EF. Determinants of polypharmacy and compliance with GOLD guidelines in patients with chronic obstructive pulmonary disease. Int J Chron Obstruct Pulmon Dis 2011;6:493-501.

27. Tyagi N, Gulati K, Vijayan VK, Ray A. A study to monitor adverse drug reactions in patients of chronic obstructive pulmonary disease: Focus on theophylline. Indian J Chest Dis Allied Sci 2008;50:199-202.

28. Karner C, Chong J, Poole P. Tiotropium versus placebo for chronic obstructive pulmonary disease. Cochrane Database Syst Rev 2012;7:CD009285.

29. Tonnel AB, Perez T, Grosbois JM, Verkindre C, Bravo ML, Brun M, et al. Effect of tiotropium on health-related quality of life as a primary efficacy endpoint in COPD. Int J Chron Obstruct Pulmon Dis 2008;3:301-10.

30. Tashkin DP, Celli B, Senn S, Burkhart D, Kesten S, Menjoge S, et al. A 4-year trial of tiotropium in chronic obstructive pulmonary disease. N Engl J Med 2008:359:1543-54.

31. Tsiligianni I, Kocks J, Tzanakis N, Siafakas N, van der Molen T. Factors that influence disease-specific quality of life or health status in patients with COPD: A review and meta-analysis of Pearson correlations. Prim Care Respir J 2011;20:257-68.

32. Engström CP, Persson LO, Larsson S, Sullivan M. Health-related quality of life in COPD: Why both disease-specific and generic measures should be used. Eur Respir J 2001;18:69-76.

33. Pickard AS, Yang Y, Lee TA. Comparison of health-related quality of life measures in chronic obstructive pulmonary disease. Health Qual Life Outcomes 2011;9:26.

How to cite this article: Mishra VR, Patel PP, Kumar DR, Patel CH. A study of the drugs used in chronic obstructive pulmonary disease and their impact on quality-of-life. Int J Med Public Health 2014;4:343-9.

Source of Support: Nil, Conflict of Interest: The authors declared no conflicts of interest. 